G. T. Prior published his "Catalogue of Meteorites" in 1923 it held a clear lead over all othors. In the past thirty-five years, the intensive search for meteorites sponsored by Dr. H. H. Nininger in the United States has resulted in a large number of new finds, but has also made the acquisition of new falls by purchase increasingly difficult for the Museum. Although a programme of exchanges with other museums has been vigorously pursued, the increase in falls represented in the British Museum has hitherto not kept pace with the increase in known falls. The scientific aspect of the Nuffield gift is of importance because meteorites constitute the only extra-terrestrial material available for detailed study, and an exact knowledge of their composition and structure is important for the cosmogony of the solar system.

\section{Skomer Island as a Nature Reserve}

WrTH the co-operation of the West Wales Field Society, the Nature Conservancy is purchasing the island of Skomer as a National Nature Reserve. Skomer, 722 acres, is the largest of the islands off the Pembrokeshire coast. It is the landward edge of the ridge of varied igneous rocks of Ordovician age, jutting west from the mainland through Skomer to form Grassholm (famous for its colony of 10,000 pairs of gannets). Each year great numbers of sea-birds breed on Skomer, as well as a strong colony of the Atlantic grey seal. Probably the most notable breeding species is the Manx shearwater, a bird scarcely found on the mainland, but nesting in tens of thousands on Skomer and Skokholm. The puffin colony is, next to that of St. Kilda in the Hebrides, probably the largest in the British Isles. The island is also well known for the Skomer vole, which differs from the common bank vole in its larger size, extreme tameness and brighter colour. Skomer is being leased to the West Wales Field Society, which made an extensive field survey of the island in 1946, deseribed in "The Island of Skomer" (West Wales Field Society, Orielton, Pembroke, 1950. 18s.). Persons requiring facilities on the island should communicate in advance with the Society, c/o The Hon. Warden, Orielton, Pembroke. Scientific investigations on the reserve may be arranged with the Regional Officer for South Wales of the Nature Conservaney, Department of Zoology, University of Swansea, Singleton Park, Swansea.

\section{The British Steel Industry}

Political and Economic Planning has rendered a real service by summarizing in Broadsheet No. 428 (November 28, 1958) "The Development of the Steel Industry", without entering into political controversy regarding ownership and control, the problems involved in planning the development of the industry whatever form of organization is finally adopted. The most important issue regarding the organization of the industry is simply whether one form of organization is better able than another to help the industry to provide the steel that is needed for the growth of the rest of the economy. Decisions will be required from time to time as to the total capacity of the industry and also detailed decisions on the building of individual plants. The former will have to be based on estimates of the growth of industrial production, which in post-war conditions are exceedingly difficult to make. The latter will continue to be influenced by assessments of future prospects for supply and demand, whether the industry is privately owned and controlled, or privately owned but supervised by an official board as at present, or both publicly controlled and publicly owned. Pricing policies will affect both the total demand for all kinds of steel and the demand for particular products. Location will be a matter of controversy because argument will continue that one location is better or worse than another not only on the grounds of productive efficiency, but also on account of the social issues involved in siting such large and vital industrial units. The development of the European Economic Community and the possible association of Britain with it will affect decisions about the capacity and location of the British industry, and particularly the question of the acceptance of some imports as against the objective of self-sufficiency in steel. These are the real economic issues, and questions of ownership and control are significant economically only in so far as they contribute to their solution.

\section{Future of Television in Britain}

SOME of the factors which should be taken into account when considering the future development of television are set out in a broadsheet, "Prospects for Television" (No. 427, October 31, 1958), issued by Political and Economic Planning. Without seeking to argue that a certain type of development should occur or to suggest who would be best able to undertake it, the broadsheet shows that there are many possibilities and that television in Britain need not be as limited as is sometimes imagined. The four remaining channels in Band 3 could be used to provide another television service for most of the country as soon as the Government decided to make them available (subject to available finance), but this would utilize all available very high-frequency channels and would reinforce the strength of present standards while leaving untackled the problems of higher definition and colour and of ultra highfrequency. It might also prevent the development of colour or higher definition on very high frequency, and would leave no room for parallel transmissions if further services were required. Two programmes could be provided on the remaining very high-frequency channels, each serving nearly two-thirds of the population, while allowing some local low-powered stations of Britain, but national coverage would not be achieved and there could be no further programmes or room for manœuvre. It is unlikely that the present very high-frequency channels or their limited extension will prove adequate for the future, and the main hope seems to lie in the development of the ultra high-frequency bands, which will leave room for a wider entry and allow a higher definition system and colour to be introduced when wanted. It should be possible to have quite a number of national and local television stations if they are wanted, and the proposed extension of the hours of television would permit the provision of a wider range of programmes for differing tastes but would add considerably to costs.

\section{Nuclear Power Station on the Lleyn Peninsula}

INTENSE opposition to the building of the nuclear power station at Edern in the Lleyn Peninsula is strongly brought out in the annual report of the Caernarvonshire Branch of the Society for the Preservation of Rural Wales. To protect the beauty and tranquillity of this rare and unspoilt coast, the National Parks Commission declared it an "area of outstanding natural beauty" on September 13, 1956 ; this was confirmed by the Minister of Fuel and 